\title{
UNIVERSIDADE FLEXÍVEL: NOVA TENDÊNCIA PARA AS UNIVERSIDADES FEDERAIS BRASILEIRAS
}

\author{
UNIVERSIDAD FLEXIBLE: NUEVA TENDENCIA PARA LAS UNIVERSIDADES \\ FEDERALES BRASILEÑAS
}

\author{
FLEXIBLE UNIVERSITY: NEW TRENDS FOR BRAZILIAN FEDERAL \\ UNIVERSITIES
}

Alda Maria Duarte Araújo CASTRO ${ }^{1}$ Raphael Lacerda de Alencar PEREIRA ${ }^{2}$

RESUMO: Analisa a flexibilização das instituições públicas federais de educação superior no âmbito do Programa de Apoio a Planos de Reestruturação e Expansão das Universidades Federais (Reuni). Trata-se de um estudo de caso realizado na Universidade Federal do Rio Grande do Norte, tendo como referência a criação do Curso de Bacharelado de Ciências e Tecnologia, cujo formato é interdisciplinar e em regime de ciclos. Os resultados evidenciam mudanças na gestão institucional, na flexibilização das estruturas acadêmicas com repercussão nas políticas expansionistas da instituição.

PALAVRAS-CHAVE: Reforma gerencial. Política educacional. Educação superior. Flexibilidade acadêmica.

RESUMEN: Analiza la flexibilización de las instituciones públicas federales de educación superior en el ámbito del Programa de Apoio a Planos de Reestruturação e Expansão das Universidades Federais (Reuni). Se trata de un estudio de caso realizado en la Universidade Federal do Rio Grande do Norte teniendo como referencia la creación del Curso de Bacharelado em Ciências e Tecnologia, con formato interdisciplinar y en régimen de ciclos. Los resultados evidencian cambios en la gestión institucional, en la flexibilización de las estructuras académicas con repercusión en las políticas expansionistas de la institución.

PALABRAS CLAVE: Reforma gerencial. Política educacional. Educación. Superior. Flexibilidad académica.

ABSTRACT: It analyzes the federal universities flexibilization considering the scope of the Support Program to Restructuring and Expansion Plans of the Federal Universities (Reuni). It is a study case carried out at the Federal University of Rio Grande do Norte, specifically with the creation of a Bachelor's Degree in Science and Technology in an interdisciplinary and

\footnotetext{
${ }^{1}$ Universidade Federal do Rio Grande do Norte (UFRN), Natal - RN - Brasil. Atualmente é professora Associada da e Professora do Programa de Pós-graduação em Educação da UFRN. ORCID: http://orcid.org/ 0000-00016740- 6257. E-mail: aldacastro01@ hotmail.com.

${ }^{2}$ Universidade Federal do Rio Grande do Norte (UFRN), Natal - RN - Brasil. Doutorado na Universidade Federal do Rio Grande do Norte. ORCID: http://orcid.org/0000-0001-8066-4250. E-mail: raphaelldap@ gmail.com
} 
cycle-based format. The results shows changes in the institutional management, the flexibility of the academic structures with repercussions on the institution expansionist policy.

KEYWORDS: Management reform. Educational politics. College education. Academic flexibility.

\section{Introdução}

Os atuais processos de reforma pelas quais passam os sistemas educacionais devem, necessariamente, ser compreendidos em um contexto mais amplo de reestruturação do Estado. Isso nos leva a entender que a história não se constitui, apenas, de continuidades, mas também de um complexo processo de tensões e rupturas, em que as mudanças vivenciadas ultrapassam fronteiras geográficas e se integram a um capital em constante expansão. Nas últimas décadas, a implantação do ideário neoliberal propiciou mudanças estruturais que, relacionadas ao processo de globalização e com o advento de novas tecnologias, repercutiram em todos os setores da sociedade.

No campo da gestão pública, os paradigmas de organização do serviço público foram modificados; desse modo, vem se consolidando um modelo de gestão que prioriza os princípios gerenciais, oriundos de empresas privadas, que propõe ideias modernizadoras e reformistas. Entre os princípios da nova governabilidade gerencial seria necessário que a alta burocracia, na perspectiva dos novos padrões e ideologia, formulasse, supervisionasse e regulasse a política visando conduzir a mudança desejada.

O artigo pressupõe que as modificações ocorridas no campo da gestão pública são oriundas de um cenário global com repercussões no contexto latino-americano; dessa forma, os Estados tiveram que se reformar para se adaptar ao novo modelo de gestão que estava sendo implementado. Como parte das ações do Estado, as universidades públicas brasileiras sofreram forte impacto e foram induzidas a adotar uma matriz gerencial na condução dos seus serviços, com o objetivo de se tornarem mais flexíveis e orientadas ao mercado.

Para a análise dessa temática, o estudo se estrutura em três seções. A primeira discute os princípios organizativos da gestão gerencial, com destaque para as características da flexibilização institucional; a segunda analisa a influência das diretrizes da Universidade Nova no Programa de Apoio a Planos de Reestruturação e Expansão das Universidades Federais (Reuni); e, a terceira seção discute o processo de reorganização da Universidade Federal do Rio Grande do Norte (UFRN) com base em novos arranjos institucionais, operacionalizados no Bacharelado de Ciências e Tecnologia (BCT). 


\section{Orientações teóricas para a modernização da gestão pública: diretrizes para o contexto latino-americano}

Nas últimas décadas do século XX, tendo como referência as mudanças ocorridas nas sociedades contemporâneas, novas concepções de gestão foram se consolidando para responder às demandas do mundo produtivo. É importante esclarecer que o processo de discussão no campo teórico, no que se refere à gestão da Res pública, está estreitamente relacionado com as complexas mudanças estruturais pelas quais passa o Estado moderno, apontado como responsável pelas crises inerentes ao modo de produção capitalista. Um dos argumentos apresentados para superação dessa crise seria que o Estado deveria se tornar mais ágil, mais eficiente e produtivo na busca da satisfação dos cidadãos, o que demandaria uma mudança do modelo burocrático de gestão.

A reforma do Estado tem sua dinâmica determinada por mudanças ocorridas na organização da produção e nas relações de poder que levaram à redefinição das estratégias econômicas e político-sociais do Estado nas sociedades capitalistas. De acordo com as propostas neoliberais (FRIEDMAN, 1988), entre os motivos para a crise do capital estariam o crescimento do Estado burocrático, a excessiva intervenção do Estado na economia e, ainda, a baixa qualidade na prestação de serviços públicos.

Nesse contexto, questões como: a descentralização administrativa e política; a atribuição de funções e autonomia ao mercado e à sociedade; a flexibilização da gestão e, entre outras, a preocupação com a eficiência na busca de resultados, tornam-se centrais, sendo relacionadas, segundo Costa (2010, p. 139), à “emergência de um novo paradigma em administração pública, rotulado de modelo gerencialista ou new public management".

No novo modelo, a lógica do mercado deve se sobrepor ao Estado e adquire relevância a ideia de que é imprescindível modernizar e flexibilizar a organização estatal; a reforma deveria criar condições para um incremento expressivo, tanto da governança (capacidade de implementar políticas públicas) quanto da governabilidade (condições institucionais de legitimação). A reforma foi concebida para promover um incremento significativo do desempenho estatal mediante a introdução de formas inovadoras de gestão e de iniciativas destinadas a quebrar as "amarras do modelo burocrático", a descentralizar os controles gerenciais, a flexibilizar normas, estruturas e procedimentos (NOGUEIRA, 2005).

Para Bresser-Pereira (2006, p. 9), havia necessidade, na América Latina, de ajustes fiscais a curto prazo, para equilibrar a balança de pagamentos. As primeiras orientações, denominadas de "reformas de primeira geração", foram orientadas para o mercado - 
principalmente a liberalização comercial e a privatização. Ainda que o ideário neoliberal tenha conseguido algum êxito no caso latino-americano, relacionado, em grande medida, à diminuição dos altos índices de inflação, convém destacar que não ocorreu o crescimento econômico esperado, e as enormes desigualdades sociais permanecem como características marcantes do continente.

Na segunda metade da década de 1990, quando as propostas neoliberais começam a mostrar sinais de crise, o tema da reforma do Estado, com forte influência do Banco Mundial, vai ganhando espaço e adquire novas proporções, associado ao discurso de que era necessário que as reformas contemplassem outros aspectos da gestão pública para tornar os governos mais eficientes no provimento das políticas e também mais responsáveis com as demandas dos cidadãos. Essa orientação levou a um novo programa prescritivo que pode ser chamado de "reformas de segunda geração" (ARAÚJO, 2010).

O Conselho Diretivo do Centro Latino-Americano de Administração para o Desenvolvimento (CLAD), aprovou, em 1998, o documento intitulado: “Uma Nova Gestão Pública para a América Latina”. O documento aponta para a necessidade de comprometimento do Estado com as questões sociais (universalidade dos serviços de saúde e educação, por exemplo), no entanto, é importante ressaltar que sua função deveria se concentrar nas atividades de regulação. Dessa forma, as privatizações e a criação de agências reguladoras são parte importante desse projeto, tendo em vista que o Estado deve "desenvolver sua capacidade estratégica de atuar junto ao setor privado e à universidade para criar um entorno adequado ao aumento da competitividade das empresas" (CLAD, 1998, p. 28).

No contexto do debate sobre a crise da gestão pública, buscando alternativas para superar tanto a gestão tradicional quanto o gerencialismo clássico ${ }^{3}$, surge uma tendência que agrega um conjunto importante de ideias - a Nova Gestão pública - "NGP”, que, segundo Nogueira (2005), fixou-se mundialmente entre as décadas de 1980 e 1990 como um novo paradigma no terreno da gestão pública, tendo como hipótese principal uma forte valorização dos mecanismos de mercado, que seriam mais eficientes para racionalizar procedimentos, organizar atividades e controlar grupos de interesses, burocratas e políticos gastadores.

Embora o interesse pela eficiência no setor público tenha como influência o setor privado, e a busca de instrumentos para melhorar os processos administrativos não seja uma novidade, a proposta da Nova Gestão Pública vai além, ou seja, supõe uma significativa

${ }^{3}$ Gerencialismo Clássico atribuído às primeiras iniciativas de organização da gestão pós-burocrática para a estruturação e a gestão da administração pública baseada em valores de eficiência, eficácia e competitividade. 
mudança de perspectiva sobre a maneira de alcançar resultados no âmbito público, o que, por sua vez, acaba por afetar a própria definição de público (OLÍAS DE LIMA, 2001).

As bases teóricas do novo gerencialismo são, para Costa (2010), produto de uma longa maturação de ideias, oriundas dos meios acadêmicos desde a década de 1950. Esse modelo de intervenção, que não nasceu do neoliberalismo, mas foi por ele apropriado, é a aplicação ao campo da gestão pública de "ganhos teóricos" da nova economia política e da ciência política, traduzidos, por sua vez, em políticas de gestão pública, identificadas com posições partidárias (relevante conteúdo ideológico).

Araújo (2010, p. 145) complementa a discussão e expõe as principais características da Nova Gestão pública quando afirma que:

[...] constituem ideias centrais da Nova Gestão pública um Estado administrativo ao estilo da iniciativa privada; contratos de gestão entre unidades; avaliação de desempenho; ênfase em resultados; redução do poder da burocracia; focalização na eficiência; busca de mecanismos regulatórios; introdução sistemática de conceitos de produtividade; flexibilidade; competitividade administrada; participação dos agentes sociais e controle dos resultados; foco no cidadão, orçamento e avaliação por resultados e performance; fortalecimento e aumento da autonomia da burocracia; descentralização na formulação e execução de políticas e por fim maior autonomia às unidades executoras.

No continente latino-americano, essas características podem ser observadas, por exemplo, nas diretrizes expostas pelo Centro Latino-Americano de Administração para o Desenvolvimento (CLAD, 1998), quando apontava, às vésperas do século XXI, que a "reforma do Estado tornou-se o tema central da agenda política mundial" (CLAD, 1998, p. 27). Em todos os países desenvolvidos ou em desenvolvimento foram empreendidas reformas do aparelho do Estado com o intuito de introduzir mudanças consideradas essenciais para modernizar o funcionamento das burocracias estatais.

No Brasil, o esforço governamental no terreno da reforma administrativa possibilitou o estabelecimento de novos parâmetros para pensar a gestão pública com base em uma hipervalorização da administração empresarial, privilegiando o mercado; criou focos de incentivo para a atualização do modelo burocrático, aumentou o controle social e a incorporação de mecanismos de participação e de descentralização na gestão das políticas públicas com sérias repercussões nas políticas educacionais.

\section{Inovações na estrutura acadêmica da instituição universitária brasileira}


Em consonância com as tendências divulgadas pelos movimentos reformistas nos países centrais, o Brasil vem protagonizando um expressivo processo de reforma em suas políticas para a educação superior, com diversas implicações para a reestruturação e expansão das instituições universitárias federais no país. Considerando as particularidades da reforma da educação superior brasileira, é pertinente analisar a proposta apresentada pelo professor Almeida Filho, na época, Reitor da Universidade Federal da Bahia, denominada "Universidade Nova", que buscava alterar a "estrutura acadêmica" das instituições universitárias, implementando a ideia da formação em regime de ciclos. O documento "Manifesto da Universidade Nova: Reitores de Universidades Federais Brasileiras pela Reestruturação da Educação Superior no Brasil" foi assinado, em 2006, por dirigentes das instituições universitárias brasileiras.

Reconhecendo a importância de reformar a educação superior e, em grande medida, tomando como referência os modelos educacionais dos países centrais, o documento (2006) apontava algumas diretrizes para a reforma, entre elas: a) revisão dos currículos e projetos acadêmicos para flexibilizar e racionalizar a formação de profissional (perspectiva multi e interdisciplinares); b) formulação e fomento a programas de intercâmbio de âmbito regional, nacional e internacional, promovendo a mobilidade de estudantes, professores, pesquisadores e servidores técnico-administrativos; c) adequação às demandas da Sociedade do Conhecimento e de um mercado de trabalho marcado pela desregulamentação, flexibilização e imprevisibilidade, adotando, na Universidade brasileira, uma concepção acadêmica, pautada em modelos de estudos de graduação de maior abrangência; d) promoção de iniciativas que possibilitassem novas arquiteturas acadêmicas para as instituições brasileiras, convergindo para um modelo unificado, capaz de integrar os diversos regimes curriculares e sistemas de títulos (compatibilidade com os espaços internacionais).

Nesse sentido, a formação em nível superior consistiria em três ciclos, começando por um Bacharelado Interdisciplinar $\left(1^{\circ} \mathrm{Ciclo}\right)$ que propiciaria uma formação universitária geral, podendo ser terminativa ou como pré-requisito para progressão aos ciclos seguintes. A Formação Profissional $\left(2^{\circ} \mathrm{Ciclo}\right)$ poderia ser realizada em licenciaturas ou carreiras específicas e, por fim, a Pós-Graduação ( $3^{\circ}$ Ciclo) ofereceria a formação acadêmico-científica e profissional em nível de pós-graduação.

Essa estrutura acadêmica apresenta diversas similaridades com a estrutura curricular proposta pelos organismos ${ }^{4}$ internacionais e implantada pelo Processo de Bolonha no contexto

${ }^{4}$ No contexto da reforma universitária em curso, vale destacar novos modelos de ensino de graduação, com educação geral e regime de ciclos, compatíveis com os modelos curriculares dos países da Organização para 
do Espaço Europeu de Ensino Superior. A proposta dos Bacharelados Interdisciplinares (BI) tem como objetivo a flexibilização dos currículos, com a finalidade de oportunizar uma base de formação geral como requisitos para a graduação de carreiras profissionais e para a formação acadêmica de pós-graduação.

A proposta de Bacharelados Interdisciplinares (BI) reuniu, na mesma modalidade de curso de graduação, características tais como: a ampliação de conhecimentos e competências cognitivas dos estudos superiores, a flexibilização do currículo com componentes optativos, dispositivos para integrar conteúdos disciplinares e, ainda, adiamento de escolhas profissionais precoces.

De acordo com a proposta da Universidade Nova, o modelo brasileiro deveria se orientar tomando, por base, as influências do Modelo norte-americano, oriundo da reforma flexneriana ${ }^{5}$, e, por outro lado, considerando a estrutura do Modelo Unificado Europeu, implantado pelo Processo de Bolonha (1999), sem, no entanto, significar uma submissão a essas propostas.

Essa junção de modelos distintos para a reestruturação da educação superior impulsionou diversas críticas à proposta, considerando que no modelo "flexneriano" ocorre uma dicotomia entre a formação profissional e a acadêmica, tendo em que vista que o aluno, buscando ingressar rapidamente no mercado de trabalho, frequenta os "Colleges", que são instituições não universitárias com formação mais aligeirada e com duração média de dois anos. Esse processo se agrava porque, propondo uma formação unificada na graduação ( $\left(1^{\circ} \mathrm{Ciclo}\right)$, a possibilidade de entrada na pós-graduação ocorre em um período de tempo extremamente reduzido, quando o egresso não é direcionado para as demandas do mercado produtivo.

O projeto da Universidade Nova, pedagogicamente vinculado às ideias de John Dewey e às contribuições do pragmatismo, ressalta a importância do "saber fazer" e mostra uma sintonia com os documentos elaborados por diversos organismos internacionais. A influência do pensamento de Dewey, centrando o ensino no aluno, destaca a importância da aplicação de audiovisuais no processo de ensino-aprendizagem, com o uso de metodologias que impulsionem a autonomia dos estudos. No contexto brasileiro, anteriormente, esse movimento

Cooperação e Desenvolvimento Econômico (OCDE), como os bacharelados interdisciplinares (BI) e similares (ALMEIDA FILHO; COUTINHO, 2011, p. 5).

${ }^{5}$ Em 1910, foi publicado o estudo Medical Education in the United States and Canada - A Report to the Carnegie Foundation for the Advancement of Teaching, que ficou conhecido como o Relatório Flexner (Flexner Report) e é considerado o grande responsável pela mais importante reforma das escolas médicas de todos os tempos nos Estados Unidos da América (EUA). O adjetivo "flexneriano" é aplicado, geralmente, com caráter pejorativo aos currículos (médicos) que apresentam uma divisão clara entre um período ou ciclo inicial de disciplinas básicas, seguido de outro dedicado aos estudos clínicos (PAGLIOSA; DA ROS, 2008). 
esteve relacionado à chamada Escola Nova, com participação de Anísio Teixeira, defendendo a atividade prática e a democracia como indispensáveis ao processo educativo.

Partindo de uma crítica ao atual modelo dominante nas universidades brasileiras e denunciando, entre outras variáveis, a profissionalização precoce, a seleção limitada e excludente para ingresso na graduação, a grande distância entre graduação e pós-graduação, Almeida Filho (2007, p. 4), defendendo as diretrizes para a implementação do seu projeto, afirma que:

[...] a proposta hoje denominada de Universidade Nova aponta para uma transformação radical da atual arquitetura acadêmica da universidade brasileira. [...] A introdução do regime de ciclos implicará ajuste da estrutura curricular tanto dos cursos de formação profissional quanto da pós-graduação. [...] Pretende-se, dessa maneira, construir no Brasil um modelo de educação superior compatível, no que for vantajoso para o contexto nacional, com o Modelo Norte-Americano (de origem flexneriana) e com o Modelo Unificado Europeu (Processo de Bolonha).

Além do argumento da necessidade de compatibilização curricular (Bolonha e EUA), o outro argumento fundamental utilizado para justificar a necessidade da implantação da Universidade Nova é o de que, atualmente, os estudantes são obrigados a escolher precocemente a profissão e isso tem resultado em altos índices de evasão. Segundo Tonegutti e Martinez (2007), esse argumento pode ser considerado uma falácia, visto que é colocado como se fosse verdadeiro, sem a apresentação de qualquer dado concreto de pesquisa que possa respaldá-lo.

Ressaltando em uma importante crítica a esse modelo proposto, Lima, Azevedo e Catani (2008) entendem que, com a Universidade Nova, o Brasil corre o risco de promover a transformação de suas universidades públicas federais em "Liberal Arts Colleges", abrindo mão de alcançar o padrão de qualidade das universidades de primeira linha dos EUA ${ }^{6}$. De acordo com esses autores, considerando os complexos desafios institucionais, as mudanças organizacionais não levarão, facilmente, à renovação da universidade brasileira:

A universidade é o lugar da insatisfação e da crítica constante. A simples mudança da arquitetura curricular da universidade não a torna uma universidade nova. A universidade brasileira para se renovar precisa tomar a lição histórica de Humboldt, o que não se traduz por germanizar-se, norteamericanizar-se ou europeizar-se. A universidade humboldtiana não está

${ }^{6}$ Há muita polêmica cercando estas instituições, desde o final do século XIX quando surgiram, até os dias de hoje. Alguns pesquisadores dizem que a ideia original era democratizar o acesso ao ensino superior, enquanto outros afirmam que são fruto de movimento das elites intelectuais para a reforma do ensino superior americano com o objetivo de barrar o acesso de estudantes oriundos da classe trabalhadora, ou com menos vocação para carreiras que requerem uma atividade intelectual mais intensa, das Universidades mais conceituadas ou tradicionais (TONEGUTTI; MARTINEZ, 2008). 
esgotada no Brasil, não se podendo abortar um projeto de universidade que ainda está em gestação e, mesmo assim, tem gerado ciência e massa crítica para o País (LIMA; AZEVEDO; CATANI, 2008, p. 29 e 30).

É fundamental reiterar esse posicionamento, considerando que, em países periféricos como o Brasil, há um imperativo de se preservar uma educação superior de qualidade centrada em instituições universitárias que vinculem o ensino, a pesquisa e a extensão, promovendo uma inclusão social que mantenha a educação como um bem público inalienável. Nesse sentido, o modelo proposto pela Universidade Nova, com cursos mais aligeirados, instrumentais e voltados para a integração do indivíduo ao mercado de trabalho de forma mais precoce, embora afirmando o contrário, não evidencia um modelo institucional que valorize a formação educativa desde uma perspectiva crítica e emancipadora.

De acordo com Lima, Azevedo e Catani (2008, p. 23), a "possibilidade de materialização da 'Universidade Nova' surge com a publicação do Decreto n'. 6.096, de 24 de abril de 2007, instituindo o Programa de Apoio a Planos de Reestruturação e Expansão das Universidades Federais (REUNI)". O legado da proposta “Universidade Nova”, materializado no Reuni, ocasionou uma série de modificações para a estrutura organizacional das universidades federais, sendo possível evidenciar novas diretrizes curriculares que objetivaram a implementação da flexibilização dos itinerários formativos vinculados, em muitos casos, aos Bacharelados Interdisciplinares. Nesse sentido, as instituições intensificaram os esforços para a elaboração de seus planos de reestruturação e expansão, pactuados com o MEC, colocando como central a busca pela eficiência e eficácia para alcançar as ambiciosas metas do Decreto $n^{\circ} .6 .096 / 2007$.

O Decreto que instituiu o Reuni compreende oito artigos que lançam as bases para significativas mudanças na estrutura das universidades federais, reforçando o objetivo de ampliar o acesso e a permanência na educação superior, em nível de graduação, por meio de um melhor aproveitamento dos recursos humanos existentes e da estrutura física. O Decreto $\mathrm{n}^{\circ}$. 6.096/2007 assinala suas principais diretrizes divididas em seis dimensões que, resumidamente, revelam: a) a necessidade de aumentar as vagas de ingresso (sobretudo no período noturno), redução das taxas de evasão e a ocupação de vagas ociosas; b) a ampliação da mobilidade estudantil (circulação de estudantes entre instituições, cursos e programas); c) a revisão da estrutura acadêmica (reorganização dos cursos de graduação, atualização de metodologias, busca da elevação da qualidade); d) a diversificação das modalidades de graduação; e) a ampliação das políticas de inclusão e assistência estudantil; f) a articulação da graduação com a pós-graduação e da educação superior com a básica (BRASIL, 2007). 
As diretrizes estabelecidas para o Programa, de acordo com Araújo e Pinheiro (2010), apontam para a pactuação de resultados, com metas quantitativas e qualitativas, predominando o enfoque de eficiência e flexibilidade, evidenciando uma sintonia com as propostas de inovações gerenciais de reforma do Estado. De acordo com Araújo e Pinheiro (2010), apesar de não mencionar o contrato de gestão como instrumento que passa a regulamentar as relações entre as universidades e o Ministério da Educação, o exame das diretrizes do Programa revela que, por meio desse tipo de contrato são estabelecidos objetivos, prazos, metas, indicadores, recursos e formas de avaliação. Dessa forma, estimula as universidades públicas federais a estabelecer termos de compromisso, intitulado "acordo de metas", de forma a receber verbas públicas para cumprir as metas estabelecidas contratualmente, transferindo, para a gestão pública, a lógica gerencial da administração por resultados.

O Reuni foi alvo das instituições sindicais que fizeram severas críticas ao intenso processo de racionalização a que foram submetidas as universidades públicas federais, trazendo a precarização do trabalho docente e a perda da qualidade. O Sindicato dos Docentes, ANDES (2007), ressaltou que o Programa foi uma ação de coerção que precisa ser entendida na correta dimensão da ameaça que configura, visto que pode resultar no redesenho completo da função das universidades públicas federais.

Considerando que no período FHC o investimento nas universidades federais foi precário, com orçamentos limitados em face da menor implicação estatal no provimento da educação superior pública, e que a recuperação desses investimentos, no primeiro mandato do presidente Lula da Silva, foi incipiente, o Reuni foi visto por diversos setores como alternativa importante para a expansão da infraestrutura existente e o aumento do número de vagas em cursos de graduação; por outro lado, isso dificultou a reação dos setores críticos à proposta nas IFES.

\section{A flexibilização da UFRN no âmbito do Reuni: um olhar para os Bacharelados em Ciências e Tecnologia}

A Universidade Federal do Rio Grande do Norte (UFRN) surgiu da antiga "Universidade do Rio Grande do Norte", criada pela Lei Estadual n". 2307, em 25 de junho de 1958 e federalizada pela Lei $\mathrm{n}^{\circ}$. 3.849, em 18 de dezembro de 1960. De acordo com as informações do Plano de Desenvolvimento Institucional (PDI - 2010/2019), “a partir de 1968, com a reforma universitária, a UFRN passou por um processo de reorganização que marcou o fim das antigas faculdades e escolas e consolidou a atual estrutura organizacional" (UFRN, 
2010), agrupamento de diversos departamentos que, dependendo do caráter dos cursos e disciplinas, passou a formar Centros Acadêmicos. Consolidou-se como uma instituição de caráter público, estando organizada sob a forma de autarquia de regime especial e mantida pelo Ministério da Educação. O seu Estatuto (UFRN, 2008) reforça que a "Universidade goza de autonomia didático-científica, administrativa e de gestão financeira e patrimonial, em conformidade com a Constituição Federal”.

A implementação do Reuni acarretou diversas modificações na forma de gerenciar os processos na UFRN, atribuindo grande relevância à intensificação das transformações de uma gestão burocrática para um modelo gerencial, ressaltando as práticas estabelecidas pelos contratos de gestão (Acordo de Metas). O Reuni partia da premissa de que o sistema de educação superior brasileiro ainda conservava modelos de formação acadêmica e profissional superados em muitos aspectos, tanto acadêmicos como institucionais: uma concepção fragmentada do conhecimento, currículos de graduação pouco flexíveis, com forte viés disciplinar, agravados pelo fosso existente entre a graduação e a pós-graduação herdado da reforma universitária de 1968 (BRASIL, 2007).

De acordo com esse documento, a expansão do sistema público federal de educação superior devia estar associada a "reestruturações acadêmicas e curriculares que proporcionem maior mobilidade estudantil, trajetórias de formação flexíveis, redução das taxas de evasão, utilização adequada dos recursos humanos" (BRASIL, 2007, p. 9).

No caso específico da UFRN, estruturalmente, suas unidades se organizam sob a forma de órgãos colegiados e órgãos executivos, existindo a possibilidade de que algumas delas contenham as duas modalidades. Considerando sua organização estrutural, com base nessas diretrizes e no diagnóstico das novas demandas sociais que a instituição universitária deveria atender, a UFRN elaborou suas estratégias de reestruturação nessa mesma linha de análise, ressaltando que a "estrutura acadêmica da universidade brasileira tem dificultado a implementação de projetos inovadores de ensino que possibilitem a integração do ensino com a pesquisa e a extensão" (UFRN, 2007, p. 24).

Com o intuito de superar o modelo tradicional de ensino, uma das metas previstas era a Reestruturação acadêmico-curricular; para consecução desse objetivo, o programa possibilitou, entre outras coisas, uma nova arquitetura acadêmica nos cursos de graduação, que se consolidou com a implantação dos Bacharelados Interdisciplinares. Essa proposta foi concebida de acordo com a lógica da racionalização e com o objetivo de alcançar maiores índices de certificação em menor tempo de formação. Na justificativa institucional estava a crítica aos formatos tradicionais dos cursos e ao fato de que, em alguns cursos de graduação, sobretudo nas ciências 
exatas e tecnológica, o percurso acadêmico do aluno prolongava-se, fazendo com que a sua permanência no curso atingisse o tempo máximo que lhe é permitido (UFRN, 2007). Havia um interesse institucional em ampliar significativamente a oferta de vagas em um novo formato de curso, que possibilitasse a entrada de mais de mil alunos por ano, atendidos em auditórios, com uma formação de "bacharel generalista" em três anos.

Para operacionalização desse formato de arquitetura acadêmica foi o criado o Curso de Bacharelado em Ciências e Tecnologia (BCT), e para dar suporte ao desenvolvimento das atividades acadêmicas de ensino, pesquisa e extensão do curso foi criada uma Unidade Acadêmica Especializada, a Escola de Ciências e Tecnologia (ECT), pela Resolução no . 012/2008-CONSUNI. Entre os objetivos da ECT, destacava-se "dar as condições para a implantação na UFRN da formação acadêmico-profissional em ciclos sucessivos nas áreas de ciências exatas e engenharias" (UFRN, 2013, p. 51). A "novidade" da proposta era implementar uma formação em ciclos formativos para uma diplomação intermediária do estudante, caracterizando o segundo ciclo já como um primeiro momento de educação profissional continuada. Nesse sentido, a implantação integrada do Bacharelado em Ciências e Tecnologia $(B C T)$ e da Escola de Ciências e Tecnologia (ECT) concretizou "uma tradição inovadora da UFRN no âmbito da formação de recursos humanos nas áreas de engenharias e ciências exatas", articulada ao Programa REUNI e compondo um momento "especialmente dinâmico da educação superior e da pesquisa na UFRN" (UFRN, 2013, p. 51).

O processo de formação dos alunos em uma especialidade profissional estabelece, desde o início, a ideia de "flexibilidade". Ao final do primeiro ciclo, o aluno do BCT recebe um diploma de Bacharel em Ciências e Tecnologia, de caráter generalista, na área de "Ciências Exatas e Tecnologia", possibilitando seus estudos em um segundo ciclo formativo, direcionado a uma especialidade profissional.

Para concretizar a implantação dos Bacharelados Interdisciplinares na UFRN, de acordo com as metas de expansão acordadas no Reuni, foi estabelecida a quantidade de vagas para os Cursos de Bacharelado em Ciências e Tecnologia (BCT). Considerando os vestibulares de 2010, 2011 e 2012, foram ofertadas 1.120 vagas, sendo 560 no turno noturno e 560 no turno diurno, superando em 120 vagas as cifras previstas na Proposta de Reestruturação e Expansão do Reuni (UFRN, 2007).

A materialização da implantação do BCT não prescindiu da elaboração de um currículo elaborado dentro das novas diretrizes, não mais associado a uma formação profissional específica, mas baseado no princípio da especialização progressiva (UFRN, 2007). Segundo o documento, nas áreas de Tecnologia e Ciências Exatas, "principalmente nas Engenharias, a 
evolução tecnológica tem levado ao surgimento de novas necessidades de formação profissional e, consequentemente, à criação de novos cursos", reforçando que "nestas áreas aparece com mais destaque a importância de oferecer flexibilidade na construção da formação superior ao aluno" (UFRN, 2007, p. 35).

Entre as estratégias planejadas, o BCT propunha uma formação geral nas ciências exatas fundamentais, buscando competências que o egresso complementaria, caso desejasse, em diversos campos do conhecimento profissionalizante em Engenharias e Ciências Exatas. Defendia-se que uma parte significativa do currículo do bacharelado deveria ser de livre escolha do aluno. $\mathrm{O}$ estudante poderia utilizar essas disciplinas para adiantar parte da formação profissionalizante, que poderia fazer posteriormente, ou para adaptar seu itinerário formativo aos seus interesses pessoais (UFRN, 2007). Nesse contexto, foram criados novos cursos de engenharia na UFRN, concebidos de tal forma que não precisassem oferecer a formação básica tradicional.

É importante ressaltar que essas modificações, na UFRN, ocorreram previamente às discussões referentes à necessidade de se adequar aos Referenciais orientadores para os Bacharelados Interdisciplinares e Similares das Universidades Federais, aprovado por meio do Parecer CNE/CES no. 266/2011, de 06/07/2011. Esses "Referenciais orientadores, ${ }^{7}$ para os Bacharelados Interdisciplinares e Similares” (BRASIL, 2010) representaram uma formalização institucionalizada dos princípios defendidos para a proposta Bacharelados Interdisciplinares da "Universidade Nova", reforçando ainda mais as trajetórias formativas na perspectiva de flexibilização curricular, com a diminuição de pré-requisitos, a implantação de nivelamento sem aumento de retenção e o aumento da interdisciplinaridade.

Várias foram as dificuldades de implementar esse ousado projeto de formação a partir de itinerários flexíveis em expressivas turmas da área tecnológica. Internamente, várias críticas foram realizadas, principalmente pelos alunos, no que se refere à atuação docente, como: a não utilização de metodologias que facilitassem o aprendizado, a falta de incentivo à participação nas aulas e a não coerência entre a exigência das avaliações e o conteúdo ministrado. Várias sugestões foram dadas pelos alunos para a minimização dos problemas identificados na avaliação da docência, tais como: a necessidade de reavaliação da didática utilizada pelos

${ }^{7}$ Em novembro de 2010, a Secretaria de Educação Superior encaminhou à apreciação do Conselho Nacional de Educação o documento intitulado Referenciais Orientadores para os Bacharelados Interdisciplinares e Similares no âmbito das universidades federais brasileiras. A justificativa apresentada pela SESu para encaminhamento da solicitação ao CNE se fundamentava no fato de que 15 universidades federais iniciaram a partir de 2006 a oferta de cursos de bacharelados interdisciplinares, e que já no ano de 2010, esses cursos representaram uma oferta anual de aproximadamente 9.000 (nove mil) vagas e já contam com estudantes concluintes desde setembro do ano de 2010 (BRASIL, 2011). 
professores em sala de aula; a utilização de uso frequente de exercícios com orientações claras, por exemplo, passo a passo; a necessidade de maior precisão nas explicações em sala de aula e a adoção de mecanismos para identificar o grau de apreensão e assimilação do conteúdo abordado (UFRN, 2013).

Considerando as 500 vagas oferecidas em 2009 e o número de concluintes em 2012, os dados mostram que apenas 54 alunos concluíram o curso, oriundos da primeira turma do BCT, e 96 concluíram como oriundos da segunda turma. Dos concluintes, 139 reingressaram nos cursos de segundo ciclo. Nos "cursos da área das Ciências Exatas (Estatística, Física, Matemática e Ciências Atuariais), não foram disponibilizadas vagas de reentrada pela falta de demanda" (UFRN, 2013, p. 58). Esses resultados levaram a UFRN a reavaliar os cursos, discutir os índices de retenção dos alunos, identificados nos primeiros períodos do BCT, e apresentar possíveis soluções e encaminhamentos para esse problema (UFRN, 2013, p. 58).

Essa nova arquitetura proposta no âmbito do Reuni para permitir a expansão das vagas na UFRN evidencia uma relação direta com os mecanismos institucionais discutidos no âmbito do Processo de Bolonha (1999), almejando uma flexibilização dos itinerários formativos que, no contexto brasileiro, também apareceram na proposta da Universidade Nova (2006) com a defesa da Formação em Regime de Ciclos. A relação entre a necessidade de impulsionar os processos de reestruturação acadêmico-curricular de forma articulada com as estratégias para a ampliação da oferta de vagas, no que se refere às mudanças organizacionais a partir do Reuni, atribuiu centralidade à flexibilização institucional como alternativa para suplantar as características tradicionais dos cursos de graduação.

$\mathrm{O}$ argumento que vincula a flexibilização das estruturas curriculares e a superação dos problemas institucionais tradicionalmente enfrentados nos cursos de graduação, adotando diversas orientações internacionais e nacionais para sua reestruturação, continua embasando outros processos de expansão no âmbito da formação tecnológica na UFRN.

\section{Considerações finais}

As reformas implementadas nas instituições universitárias públicas federais permitiram um crescimento institucional expressivo, tanto pela criação de instituições e cursos, como também pelo reordenamento interno das universidades. Condicionadas ao cumprimento de metas para o recebimento dos recursos financeiros adicionais, as universidades tiveram que se 
reestruturar do ponto de vista da gestão universitária, criando mecanismos que possibilitassem controlar e acompanhar o cumprimento dos resultados.

Essa dinâmica evidenciou uma das formas de implementação de novas estratégias da administração gerencial, introduzindo a lógica dos resultados nos serviços públicos por meio do constante monitoramento e controle dos resultados. Analisando as repercussões que afetaram as universidades federais, pode-se dizer que as funções dessas instituições foram sendo ressignificadas e reestruturadas por meio do princípio da racionalidade dos recursos, objetivando uma maior expansão com menor custo. Dessa forma, a educação superior passou a receber ainda mais influência das estratégias do âmbito privado, materializando nas instituições públicas diversos espaços de interseção com as práticas de mercado (mercantilização da educação) e flexibilizando internamente não apenas os aspectos institucionais (gestão e organização), mas também a própria matriz curricular dos cursos de graduação.

Especificamente, a Universidade Federal do Rio Grande adotou, como uma das estratégias de expansão, o princípio de flexibilidade curricular de cursos e programas, permitindo um amplo processo de reestruturação dos formatos institucionais, como a criação de Bacharelados Interdisciplinares em regimes de ciclos, por possibilitarem um atendimento a um grande contingente de alunos, como o Curso de Ciência e Tecnologia (BCT); a criação desse curso foi um marco na história da instituição por introduzir um modelo inovador, pautado em justificativas e reflexões sintonizadas com a realidade do ensino atual no Rio Grande do Norte e no Brasil.

Uma análise mais crítica e contextualizada permite ressaltar que o argumento que vincula a flexibilização das estruturas curriculares à superação dos problemas tradicionalmente enfrentados nos cursos de graduação nem sempre são bem-sucedidos, pois o BCT continua apresentando baixos índices de conclusão dos cursos, sérios problemas de evasão, retenção e repetência vivenciados anteriormente na UFRN nos cursos da área tecnológica.

É fundamental salientar que essas medidas relacionadas ao âmbito da gestão vão além de simplesmente buscar melhores resultados na hora de empregar os recursos públicos, refletindo um processo amplo de reestruturação que, ideologicamente, tem sérias implicações e causa profundas mudanças na compreensão do próprio modelo de universidade.

\section{REFERÊNCIAS}

ALMEIDA FILHO, N. Universidade Nova: textos críticos e esperançosos. Brasília, DF: EDU; Salvador: EDUFBA, 2007. 
ALMEIDA FILHO, N.; COUTINHO, D. Nova arquitetura curricular na universidade Brasileira. Cienc.Cult., São Paulo, v. 63, n. 1, p. 4-5, jan. 2011. Disponível em: http://cienciaecultura.bvs.br/scielo.php. Acesso: 28 set. 2018.

ARAÚJO, M. A. D. Responsabilização na administração pública: limites e possibilidades do gestor público. In: MEDEIROS, Paulo César; LEVY, Evelyn (Org.). Construindo uma nova gestão pública. Natal, RN: SEARH/RN, 2010.

ARAÚJO, M. A. D.; PINHEIRO, H. D. Reforma gerencial do Estado e rebatimentos no sistema educacional: um exame do REUNI. Enaio: aval. pol. públ. Educ., Rio de Janeiro, v. 18 , n. 69 , p. 647-668, out. 2010.

\section{ASSOCIAÇÃO NACIONAL DOS DOCENTES DO ENSINO SUPERIOR-SINDICATO} NACIONAL. As Novas Faces da Reforma Universitária do Governo Lula e os Impactos do PDE Sobre a Educação Superior. Cadernos ANDES, Brasília, n. 25, ago. 2007.

BRASIL. Decreto $n^{\circ}$ 6.096, de 24 de abril de 2007. Institui o Programa de Apoio a Planos de Reestruturação e Expansão das Universidades Federais - REUNI. Diário Oficial da União. Brasília (DF), 25 abr. 2007. Disponível em: http://www2.camara.leg.br/legin/fed/decret/2007/decreto-6096-24-abril-2007-553447-normape.html. Acesso em: 26 jan. 2019.

BRASIL. Ministério da Educação. Conselho nacional de educação. Câmara de educação superior. Parecer $n^{\circ}$ 266, de 06 de julho de 2011. ASSUNTO: Referenciais orientadores para os Bacharelados Interdisciplinares e Similares das Universidades Federais. Homologação, Despacho do Ministro. Diário Oficial da União. Brasília (DF), 14 out. 2011, seç.1, p. 16.

BRESSER PEREIRA, L. C. Apresentação. In: BRESSER-PEREIRA, Luis Carlos; GRAU, Nuria Cunill (Orgs.). Responsabilização na administração pública. São Paulo: CLAD/Fundap, 2006

\section{CENTRO LATINO-AMERICANO DE ADMINISTRAÇÃO PARA O} DESENVOLVIMENTO (CLAD). Uma nova gestão pública para a América Latina. 1998. Disponível em: http//www.bresserpereira.org.br. Acesso em: 15 jul. 2010.

COSTA, F. L. Reforma do estado e contexto brasileiro: crítica do paradigma gerencialista. Rio de Janeiro: FGV, 2010.

FRIEDMAN, M. Capitalismo e Liberdade. 3. ed. São Paulo: Nova Cultural, 1988.

LIMA, L. C.; AZEVEDO, M. L. N.; CATANI, A. M. O processo de Bolonha, a avaliação da educação superior e algumas considerações sobre a Universidade Nova. Avaliação, Campinas, v.13, n.1, p.7-36, mar. 2008.

NOGUEIRA, M. A. Um Estado para a sociedade civil: temas éticos e políticos da gestão democrática. 2. ed. São Paulo: Cortez, 2005.

OLÍAS DE LIMA, B. La evolución de la gestión pública: la nueva gestión pública. In: OLÍAS DE LIMA, Blanca. La nueva gestión pública. Madrid: Pearson Educación S.A., 2001. 
PAGLIOSA, F. L.; DA ROS, M. A.. O relatório Flexner: para o bem e para o mal. Rev. bras. educ. med., Rio de Janeiro, v. 32, n. 4, p. 492-499, Dec. 2008. Disponível em: http://www.scielo.br/scielo.php. Acesso em: 27 set. 2018.

TONEGUTTI, C.; MARTINEZ, M. A Universidade Nova, o Reuni e a queda da universidade pública. Repositório UFRRJ, 2007.

TONEGUTTI, C.; MARTINEZ, M. O REUNI e a precarização nas IFES. Revista Universidade e Sociedade, ano XVII, nº 41, p. 51 a 67, jan. 2008.

UNIVERSIDADE FEDERAL DO RIO GRANDE DO NORTE (UFRN). Estatuto da Universidade Federal do Rio Grande do Norte. Natal: EDUFRN, 2002.

UNIVERSIDADE FEDERAL DO RIO GRANDE DO NORTE (UFRN). Sinopse do projeto de reestruturação e expansão da UFRN no programa REUNI (2007). 2007. Disponível em http://reuni.ufrn.br/. Acesso em: 10 abr. 2018.

UNIVERSIDADE FEDERAL DO RIO GRANDE DO NORTE (UFRN). Plano de desenvolvimento institucional 2010-2019. Natal: EDUFRN, 2010.

UNIVERSIDADE FEDERAL DO RIO GRANDE DO NORTE (UFRN). Relatório final do projeto de reestruturação e expansão (UFRN/REUNI, 2013). 2013. Disponível em http://reuni.ufrn.br/. Acesso em: 10 abr. 2018.

\section{Como referenciar este artigo}

CASTRO, A. M. D. A.; PEREIRA, R. L. de A. Universidade flexível: nova tendência para as universidades federais brasileiras. Revista Ibero-Americana de Estudos em Educação, Araraquara, v. 14, n. esp. 3, p. 1638-1654, out., 2019. E-ISSN: 1982-5587. DOI: 10.21723/riaee.v14iesp.3.12738

Submetido em: 25/03/2019

Revisões requeridas: 26/04/2019

Aceito em: 30/06/2019

Publicado em: 30/08/2019 